\title{
Signals and memory in tree-ring width and density data
}

\author{
Jan Esper ${ }^{\mathrm{a}, *}$, Lea Schneider ${ }^{\mathrm{a}}$, Jason E. Smerdon ${ }^{\mathrm{b}}$, Bernd R. Schöne ${ }^{\mathrm{c}}$, Ulf Büntgen ${ }^{\mathrm{d}, e, f}$ \\ a Department of Geography, Johannes Gutenberg University, 55099 Mainz, Germany \\ ${ }^{\mathrm{b}}$ Lamont-Doherty Earth Observatory of Columbia University, Palisades, NY 10964, USA \\ ${ }^{c}$ Institute of Geosciences, University of Mainz, 55128 Mainz, Germany \\ d Swiss Federal Research Institute WSL, 8903 Birmensdorf, Switzerland \\ e Oeschger Centre for Climate Change Research, Bern, Switzerland \\ ${ }^{f}$ Global Change Research Centre AS CR, Brno, Czech Republic
}

\section{A R T I C L E I N F O}

\section{Article history:}

Received 3 March 2015

Received in revised form 3 July 2015

Accepted 3 July 2015

Available online 13 July 2015

\section{Keywords:}

Maximum latewood density

Temperature

Autocorrelation

Superposed epoch analysis

Volcanic eruption

Northern hemisphere

\begin{abstract}
A B S T R A C T
It has been suggested that maximum latewood density (MXD) should be used instead of tree-ring width (TRW) data to reconstruct post-volcanic cooling effects. A thorough assessment of high frequency signals and potentially differing memory effects in long MXD and TRW chronologies, in response to large volcanic eruptions, is still missing, however. We here present a compilation of MXD and TRW chronologies from 11 sites in the Northern Hemisphere, covering the past 750+ years, and containing significant June-August temperature signals. Basic assessment of the data using Superposed Epoch Analysis reveals a temporally extended response in TRW, by 2-3 years, to large volcanic eruptions, though post-volcanic cooling patterns vary considerably within the Northern Hemisphere network. Comparison with instrumental temperature data demonstrates the TRW chronologies underestimate cold conditions associated with large volcanic eruptions, a bias that is mitigated in the MXD data. While species composition (pine, spruce, larch) has no detectable influence on the cooling patterns, trees from high latitude sites $\left(>60^{\circ} \mathrm{N}\right)$ indicate a stronger and delayed (1-2 years) response to large eruptions, compared to the lower latitude sites $\left(<60^{\circ} \mathrm{N}\right)$. These basic findings caution against using TRW data for quantitatively estimating post-volcanic cooling and for comparison against the simulated climate effects of volcanic eruptions in models.
\end{abstract}

(c) 2015 Elsevier GmbH. All rights reserved.

\section{Introduction}

Volcanic eruptions have been identified as a major natural forcing of the climate system (Oppenheimer, 2011). The aerosols released by large, explosive eruptions tend to cool the earth's surface, but warm the lower stratosphere. Surface cooling results from scattering of incoming solar radiation, i.e. less radiation reaches the ground. Stratospheric warming is triggered by increased absorption of radiation, i.e. more radiation is transferred into sensible heat in $10+\mathrm{km}$ above ground (Robock, 2000). These processes ought to last for about three years following a large eruption that injects aerosols into the stratosphere (Cole-Dai, 2010 and references therein).

Whereas the climatic effects of volcanic aerosols are assessed based on differing lines of evidence, estimates of the magnitude and persistence of post-eruption cooling are accompanied by large uncertainties. Estimates based on the analysis of satellite and

\footnotetext{
* Corresponding author. Fax: +496131 3924735

E-mail address: esper@uni-mainz.de (J. Esper).
}

instrumental station data are constrained by the limited number of eruptions during the period of observation (Sear et al., 1987; Self et al., 1981). This limitation is overcome by using annually resolved tree-ring data covering the past centuries to millennia, thereby enabling the assessment of more eruptions and supporting the differentiation from internal climate variability (Briffa et al., 1998; D'Arrigo et al., 2009, 2013; Esper et al., 2013a,b; Fischer et al., 2007; Salzer and Hughes, 2007). However, the noise inherent to proxy data substantially increases the uncertainties of cooling estimates derived from this line of evidence.

Noise in tree-ring data can be differentiated into (i) the unexplained, non-climatic (non-temperature) variance typically reducing the magnitude of reconstructed cooling events, and (ii) biological memory effects likely biasing the persistence estimates of cooling events. While the unexplained variance and consequences thereof are widely recognized in the paleoclimatic literature (Esper et al., 2005; Lee et al., 2008; Von Storch et al., 2004), memory effects are much less acknowledged (Anchukaitis et al., 2012), even if detailed in standard dendrochronological 
Table 1

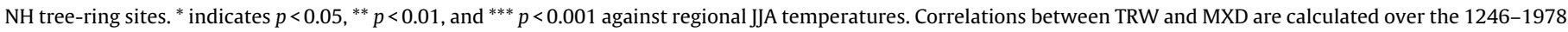
common period using Spline detrended chronologies. Sites ordered by latitude.

\begin{tabular}{|c|c|c|c|c|c|c|c|c|c|}
\hline Site & Country & Latitude & Longitude & Species & Period & Number & $\begin{array}{l}\text { JJA Signal } \\
\text { MXD }\end{array}$ & TRW & Source \\
\hline Pyrenees (Pyr) & Spain & $42.5 \mathrm{~N}$ & $2.5 \mathrm{E}$ & Pine & $1044-2005$ & 203 & $* * *$ & $* *$ & Büntgen et al. 2008 \\
\hline Lötschental (Loe) & Switzerland & $47.5 \mathrm{~N}$ & $7.5 \mathrm{E}$ & Larch & 735-2004 & 180 & $* * *$ & $* * *$ & Büntgen et al. 2006 \\
\hline Tyrol (Tyr) & Austria & $47.5 \mathrm{~N}$ & $12.5 \mathrm{E}$ & Spruce & $1047-2003$ & 227 & $* * *$ & $* * *$ & Esper et al. 2007b \\
\hline Altai (Alt) & Russia & $50.0 \mathrm{~N}$ & $88.0 \mathrm{E}$ & Larch & 462-2007 & 59 & $* * *$ & $*$ & Myglan et al. 2012a \\
\hline Athabasca (Ath) & Canada & $52.3 \mathrm{~N}$ & 117.3W & Spruce & $1072-1994$ & 102 & $* * *$ & $* *$ & Luckman et al., 2005 \\
\hline Jaemtland (Jae) & Sweden & $63.5 \mathrm{~N}$ & $15.5 \mathrm{E}$ & Pine & $1107-1978$ & 158 & $* * *$ & $* * *$ & Schweingruber et al. 1988 \\
\hline Mangazeja (Man) & Russia & $66.7 \mathrm{~N}$ & $82.3 \mathrm{E}$ & Larch/Spruce & $1246-1990$ & 143 & $* * *$ & $* *$ & Schweingruber, ITRDB \\
\hline Polar Ural (Pol) & Russia & $66.9 \mathrm{~N}$ & $65.6 \mathrm{E}$ & Larch & 778-1990 & 157 & $* * *$ & $* * *$ & Briffa et al. 1995 \\
\hline $\mathrm{N}-\mathrm{Scan}(\mathrm{Nsc})$ & Finland & $67.5 \mathrm{~N}$ & $22.5 \mathrm{E}$ & Pine & $-181-2006$ & 587 & $* * *$ & $* * *$ & Esper et al. 2012b \\
\hline Torneträsk (Tor) & Sweden & $68.2 \mathrm{~N}$ & 19.7E & Pine & $441-2010$ & 124 & $* * *$ & $* * *$ & Melvin et al. 2013 \\
\hline Camphill (Cam) & Canada & $68.3 \mathrm{~N}$ & $133.3 \mathrm{~W}$ & Spruce & 1175-1992 & 58 & $* * *$ & $*$ & Schweingruber, ITRDB \\
\hline
\end{tabular}

literature (Cook and Kairiukstis, 1990; Fritts, 1976; Matalas, 1962; Schulman, 1956).

Previous work on memory effects in TRW and MXD chronologies is rare, and either focused on just one of the two tree-ring parameters, or in only one region or tree species. Briffa et al. (1998) used a Northern Hemisphere ( $\mathrm{NH}$ ) network of MXD chronologies covering the past 200-600 years to demonstrate the capacity of reconstructing the magnitude and geographic extent of post-volcanic cooling events. Frank et al. (2007a) assessed memory effects in TRW and MXD chronologies from the European Alps subsequent to the 1815 Tambora eruption, revealing a temporally extended response in TRW, by about 5 years, compared to MXD. D'Arrigo et al. (2013) showed a smeared and temporally extended ( $\sim 10$ years) TRW pattern in response to six major eruptions, using hemispheric scale mean TRW and MXD chronologies. Esper (2014) showed a posteruption delayed response in TRW ( $\sim 3-4$ years), compared to MXD, for a single Pinus sylvestris dataset from northern Fennoscandia encompassing 34 volcanic eruptions over the past 900 years. A large-scale assessment of TRW memory effects in response to the major eruptions of the past millennium, and differentiation from patterns retained in MXD data, has not been completed.

Memory effects in TRW data can arise from physiological processes fundamental to boreal and alpine conifers. Early work by Schulman (1956) and Matalas (1962) already suggested the storage of food products from one year to the next as the main source of non-randomness and autocorrelation in TRW timeseries. These influences appear to have less impact on MXD, representing an estimate of tracheid cell-wall growth that is more directly associated with ambient air temperature changes in cold environments (Schweingruber et al., 1978). For TRW, the storage of starch and sugar in parenchyma ray tissue, the remobilization of carbohydrates from root structures, and the development of needle
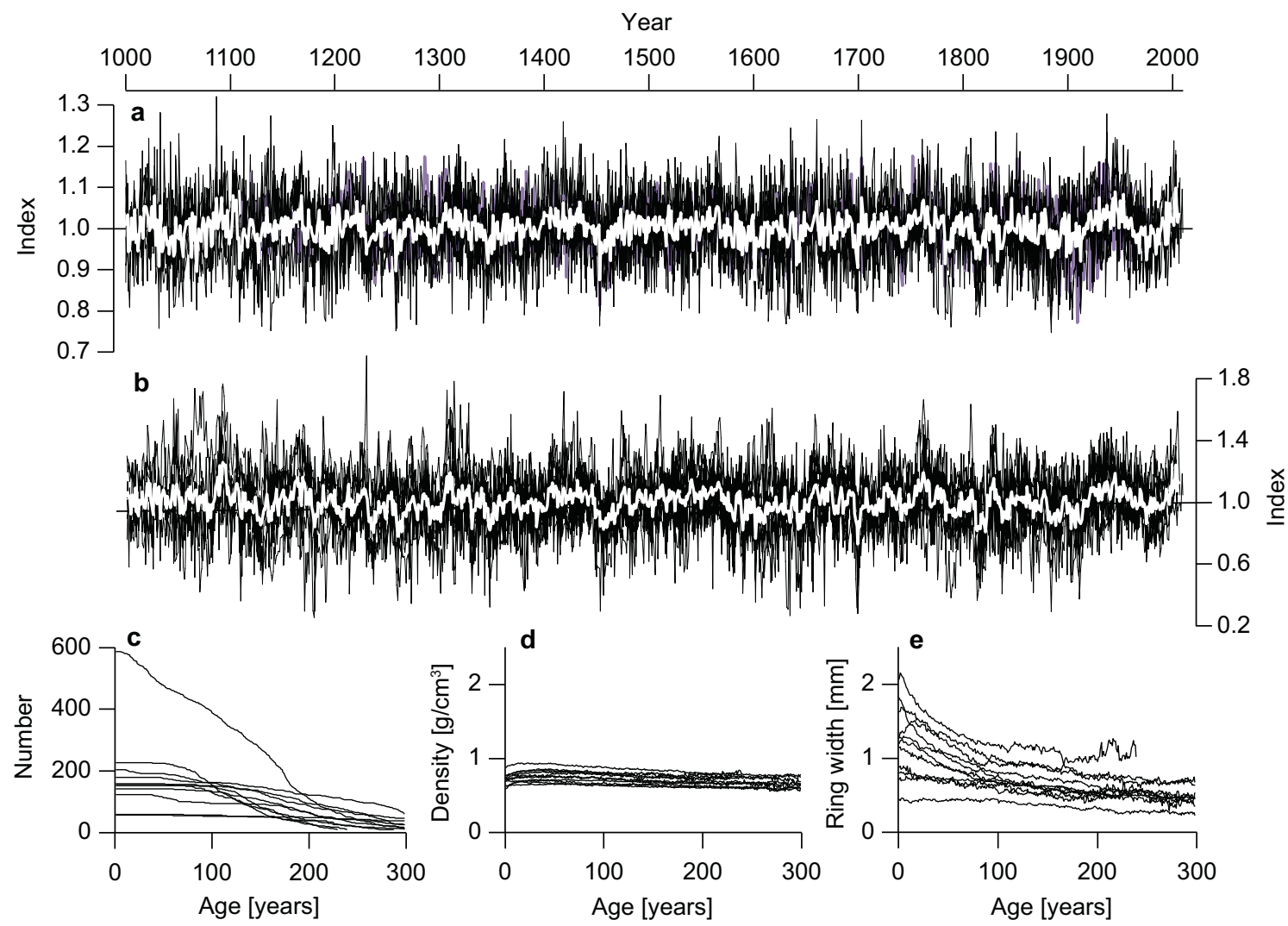

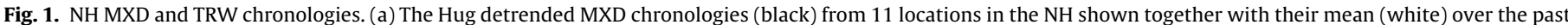

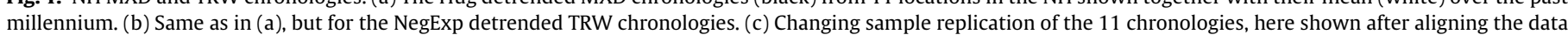

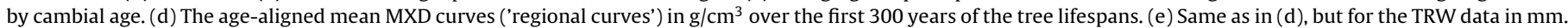



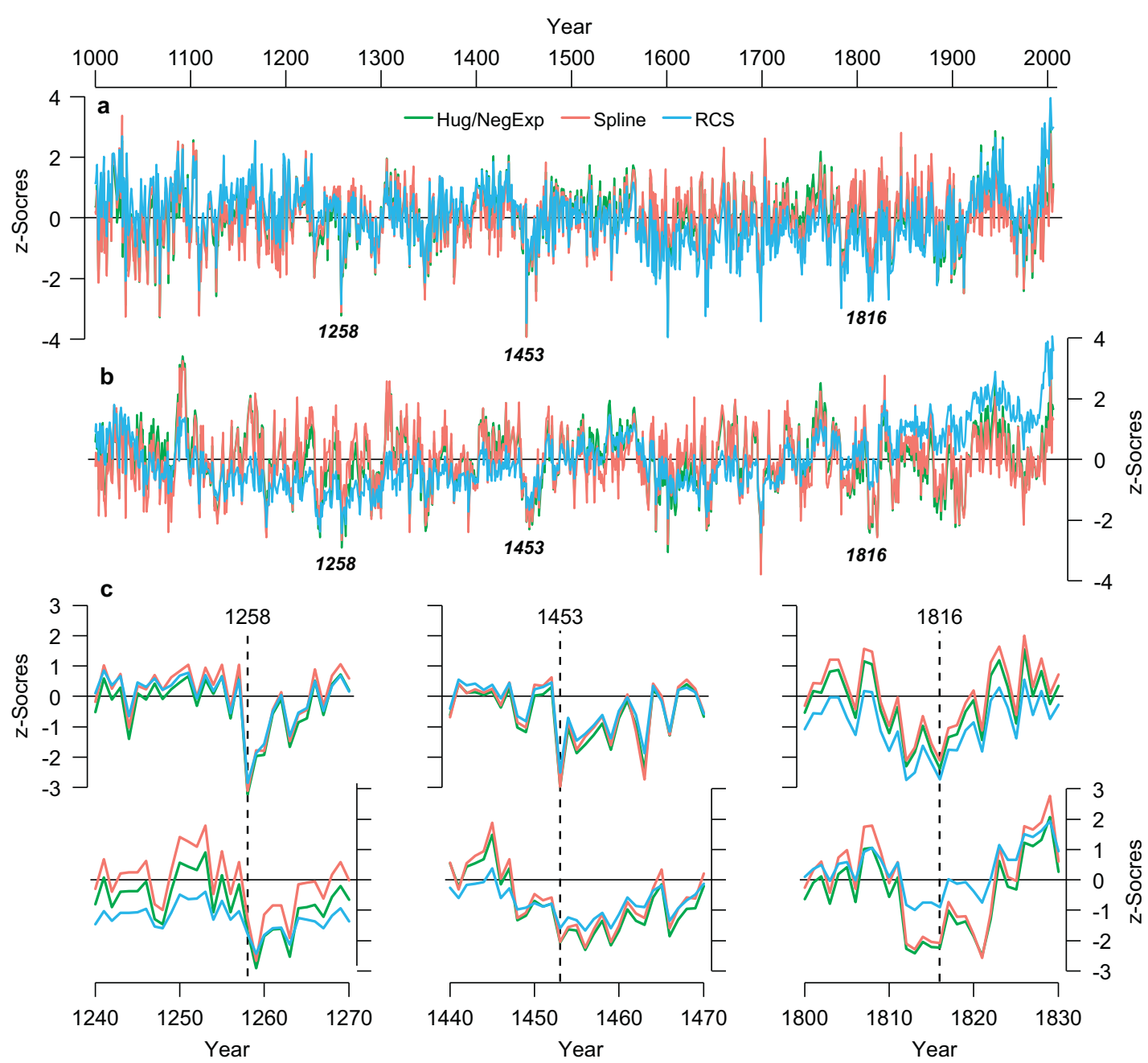

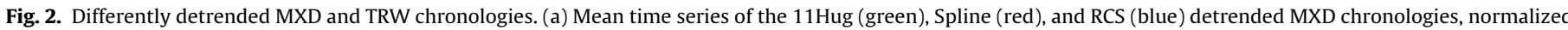

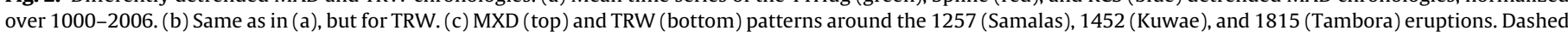
lines indicate the first post-volcanic years. Note there was an additional eruption of unknown origin in 1809.

generations enduring several growing seasons, all likely influence radial increment beyond the instant impact of temperature variability (Pallardy, 2010).

The resulting increased biological memory is imprinted upon the TRW data is reflected by an increased autocorrelation characterizing the chronologies of this parameter. While these general time series characteristics (Esper et al., 2010; Frank and Esper, 2005) and statistical treatment thereof (Cook, 1985) are detailed in the dendrochronological literature, the memory effects in response to extreme events, and underlying processes controlling this behavior, particularly for MXD, are not well understood (Vaganov et al., 2006). The application of methods to remove autocorrelation from tree-ring time series limits the ability to assess the full variance spectrum of past temperature variability (Bunde et al., 2013; Franke et al., 2013), while reconstruction methods may alone alter the scaling of spectral densities in derived dendrochronological and multi-proxy studies (Smerdon et al., 2015). The prewhitening of tree-ring chronologies to reduce biological memory and match the serial correlation of instrumental target data nevertheless has proven useful when assessing long-term hydroclimate variability (Meko, 1981). Changing the spectrum from red to white might be required to avoid low frequency bias in reconstructions of rainfall and associated hydrological phenomena (Cook and Kairiukstis, 1990 Meko et al., 2007).
We here assess high frequency signals and memory effects in MXD and TRW chronologies from $11 \mathrm{NH}$ sites covering the past $750+$ years. Consideration of these long records enables the evaluation of cooling events in response to a large number $(n=29)$ of major volcanic eruptions. Findings from this long period are compared with TRW and MXD deviations recorded since 1850, a period from which instrumental temperature data are also available. We use these data to additionally address differences between higher and lower latitude tree sites as well as the variability within the $\mathrm{NH}$ network, and discuss the results from the two tree-ring parameters with respect to their paleoclimatic significance.

\section{Material and methods}

\subsection{Tree-ring data}

The tree-ring data used here are a sub-sample of a MXD network compiled by Schneider et al. (2015) for the reconstruction of $\mathrm{NH}$ extratropical summer temperatures over the past millennium. Four of the 15 MXD chronologies included in the Schneider et al. network were not considered herin, as the accompanying TRW data from these sites did not contain a significant June-August (JJA) temperature signal. The TRW and MXD chronologies of the remaining 11 sites correlate at $p<0.05$ with regional summer temperatures, 

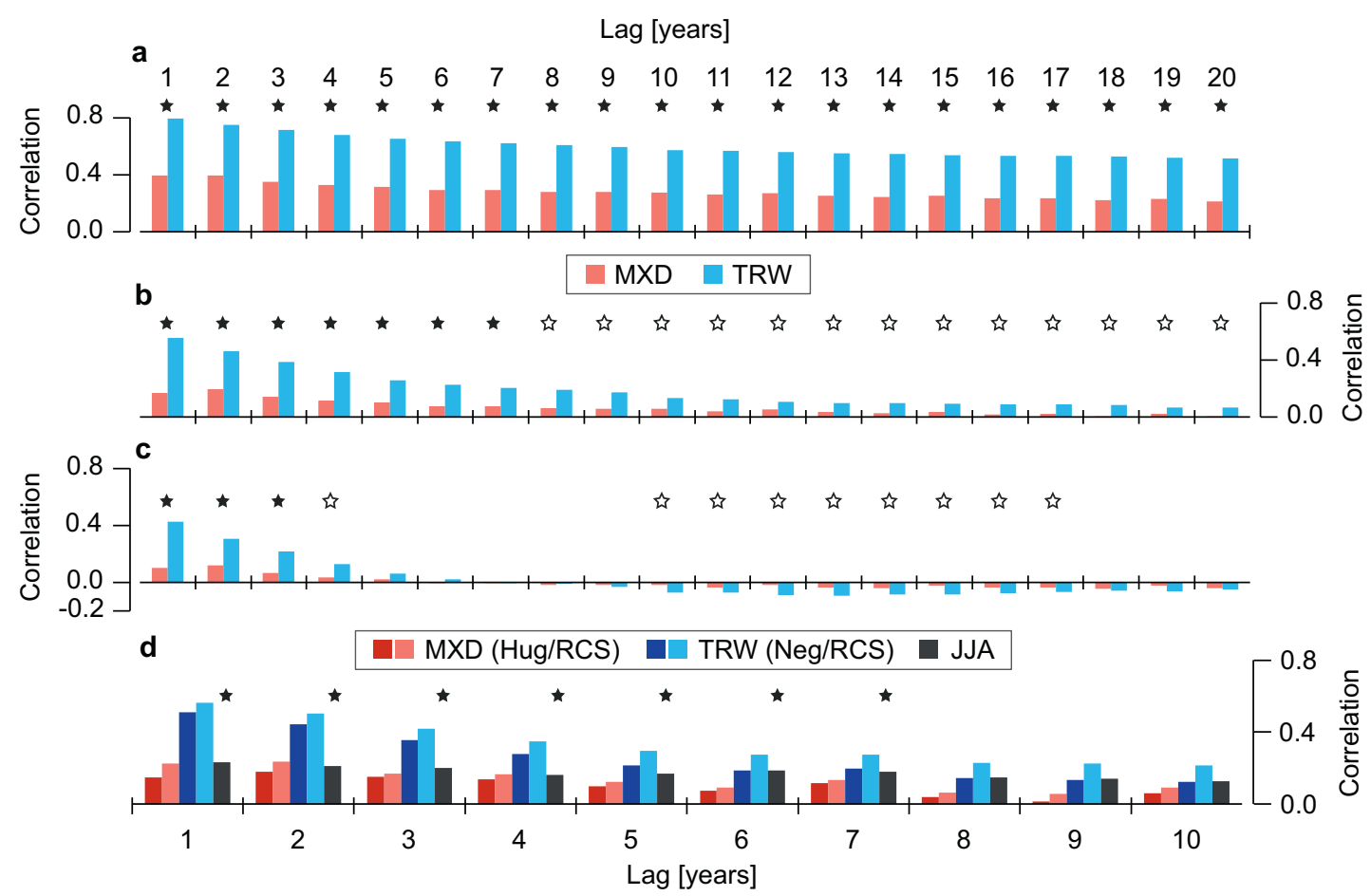

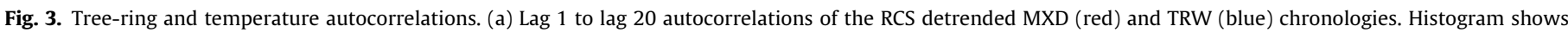

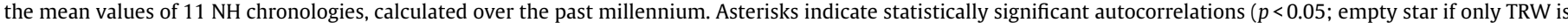

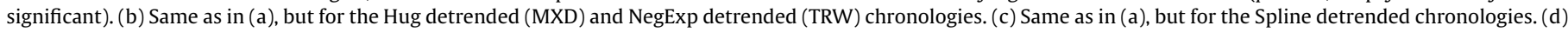

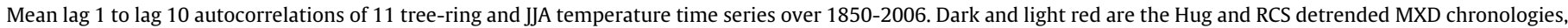
dark and light blue the NegExp and RCS detrended chronologies, and black the JJA temperatures. Asterisks indicate significant JJA temperature autocorrelations ( $p<0.05$ ).

and extend back to AD 1246 or earlier with a minimum replication $\geq 5$ series. The network includes data from pine, spruce, and larch (Table 1).

The spatial distribution of tree sites is uneven, with two sites located in Canada, three in Russia, and six in Europe. Five sites are situated south of $53^{\circ} \mathrm{N}$ at high-elevation, alpine environments. Six sites are situated north of $63^{\circ} \mathrm{N}$ in the boreal zone near the northern treeline. Sample replication and chronology length also vary considerably among the sites, with the shortest record originating from Mangazeja (Russia) and the longest from northern Scandinavia (N-Scan, Finland). The number of MXD/TRW measurement series ranges from 58 in Camphill (Canada) to 587 in northern Scandinavia, underlining the variability of the network, and indicating that climate signal strength might considerably change through time (Fig. 1).

\subsubsection{Detrending and calibration}

To assess uncertainty due to detrending methodology, the MXD and TRW data were standardized using different techniques (Fig. 2). Regional Curve Standardization (RCS; Esper et al., 2003) and 100year fixed spline detrending (Spline; Cook and Peters, 1981) were used with both parameters to emphasize low and high frequency variance, respectively. The MXD data were additionally detrended using Hugershoff functions (Hug), whereas for TRW negative exponential curves (NegExp) were chosen, to account for the differently shaped age trends (Fig. 1d and e; Cook and Kairiukstis, 1990). All methods (RCS, Spline, Hug/NegExp) were applied using residuals after power transforming the TRW and MXD data (Cook and Peters, 1997). Mean (standard) site chronologies were calculated using the arithmetic mean, and potential variance changes adjusted to account for temporal replication and inter-series correlation changes (Frank et al., 2007b).

The resulting chronologies were calibrated against instrumental JJA temperatures using the nearest grid point of the $5 \times 5^{\circ}$
CRUTEM4 v network as detailed in Schneider et al. (2015). We here considered only the tree sites at which both the MXD and TRW chronologies reached $p<0.05$ against local grid point data, after adjusting the degrees of freedom for autocorrelation in the proxy and instrumental time series (Table 1 ). While this procedure admitted tree-ring chronologies from 11 sites, it should be noted that the summer temperature signal is overall weaker in the TRW chronologies $\left(r_{-}=0.33\right)$ compared to MXD $\left(r_{-}=0.55\right)$. These estimates are conservative, however, as they do not consider any species- or sitespecific seasonality in the climate response, and are derived from correlations over the past 150 years, even in areas where early temperature readings had to be infilled using remote instrumental data (details in Schneider et al. 2015). All chronologies were transferred into estimates of past summer temperature variability by centering and scaling them to match the mean and variance of the instrumental target data back to 1850 (Esper et al. 2005).

\subsubsection{Autocorrelation and superposed epoch analysis}

Basic methods were used to assess memory effects in the TRW and MXD chronologies. We calculated the autocorrelation of the differently detrended (Hug/NegExp, Spline, RCS) chronologies over the past millennium (shorter for the records not covering the full millennium; see Table 1) at lags 1-20, and over 1850-2006 at lags $1-10$. The latter period was chosen as it additionally permits the calculation of autocorrelations of instrumental temperature data and comparison with tree-ring chronologies.

The MXD and TRW chronologies were decomposed into shorter segments of 15 years and re-aligned by volcanic eruptions using Superposed Epoch Analysis (SEA, Panofsky and Brier, 1958; see Fig. 2c for examples in 1257, 1452, 1815). For the past 1000 years, we used 27 annually dated eruptions exceeding a volcanic explosivity index (VEI, Newhall and Self, 1982) of 4 as listed by the Global Volcanism Project (Siebert et al., 2011; for a list of events of the past millennium see Esper et al., 2013b), plus the eruptions in 1257 

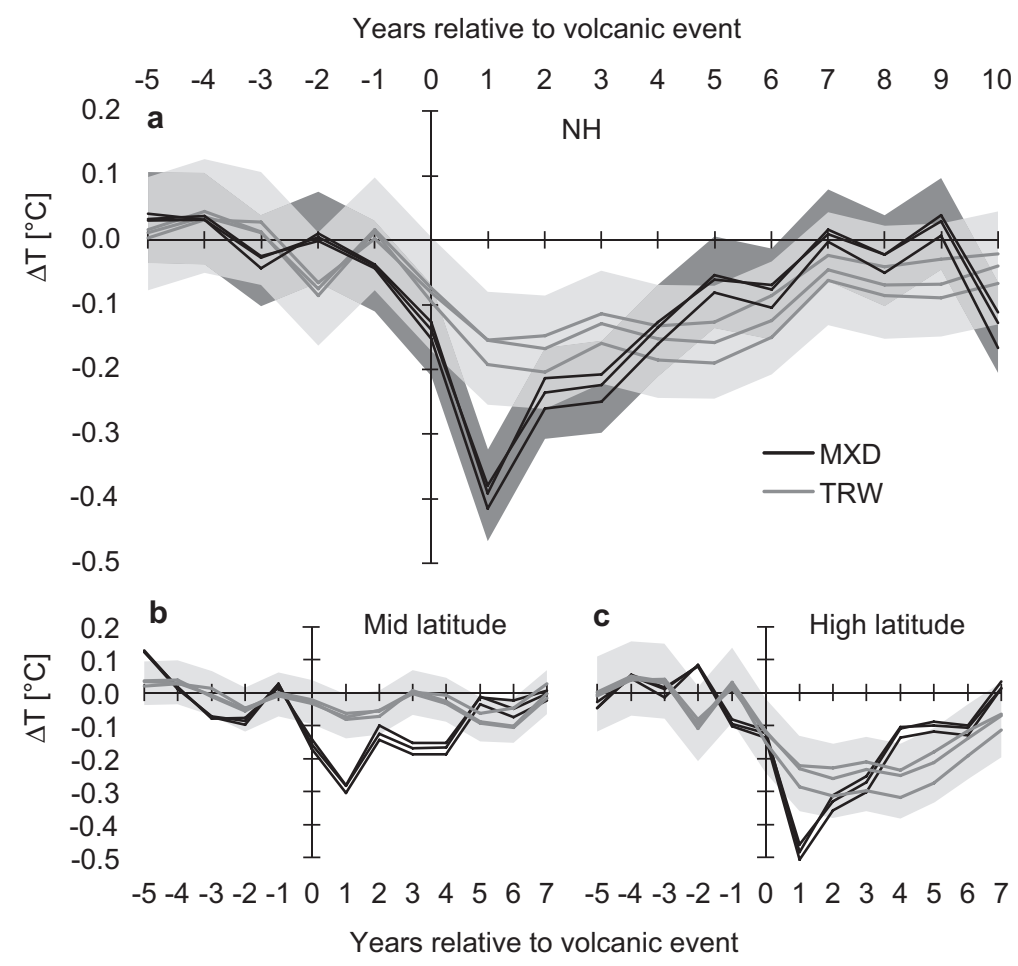

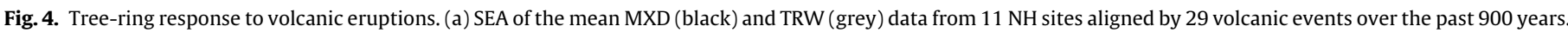

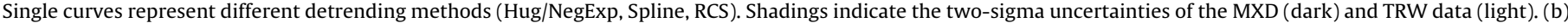
As in (a), but for five sites located south of $53^{\circ} \mathrm{N}$ (see Table 1). (c), As in (a), but for the six sites located north of $63^{\circ} \mathrm{N}$.

(Lavigne and Source of the great, 2013) and 1452 (Briffa et al., 1998) fingerprinted as aerosol deposition spikes in polar ice core data (Gao et al., 2008; Hammer et al., 1980), and annually dated through tree-ring data (Briffa et al., 1998; LaMarche and Hirschboeck, 1984). We included tropical volcanoes estimated to have released $>1$ billion $\mathrm{m}^{3}$ tephra, and $\mathrm{NH}$ extratropical eruptions $>2$ billion $\mathrm{m}^{3}$ tephra to account for the presumed increased significance of lower latitude events (Timmreck, 2012; Wegmann et al., 2014).

In addition to these evaluations using data of the past millennium, SEA was applied in the shorter 1850-2006 period, over which instrumental temperature data are available. In this second approach, we re-aligned the proxy and observational data only if local JJA temperatures exceeded $-0.5^{\circ} \mathrm{C}$ in (i) the year of a volcanic event, or (ii) in one of the two following years. In so doing, we limited this analysis to the locally cold, post-volcanic events in the 11 $\mathrm{NH}$ sites considered herein.

We finally used SEA over 1850-2006, considering the 15 coldest and warmest summers recorded in the local temperature data, and aligned the proxy data by these events instead of the volcanic eruptions. In all SEA runs, the displayed MXD, TRW, and JJA data are expressed as anomalies with respect to the five years ( -5 to -1 ) preceding a volcanic (or other) event. Statistical uncertainty was estimated considering the two sigma error range derived from the variance of the mean MXD (TRW) deviations over the five prevolcanic years $(-5$ to -1$)$ using the data of the past millennium.

\section{Results and discussion}

\subsection{TRW and Mxd autocorrelation}

The NH TRW chronologies contain substantially more autocorrelation over the past 1000 years than the MXD chronologies, independent of the method used for age-trend removal (Fig. 3). All differently detrended chronologies show the typical sequence of largest autocorrelation at lag 1 (= AC1) and subsequently decreasing values. In the RCS detrended data, the mean autocorrelation in both TRW and MXD remains positive throughout AC1-AC20, though the TRW chronologies indicate much larger temporal memory ranging from 0.79 to 0.52 (0.39 to 0.21 in MXD). In comparison, the Hug/NegExp and Spline detrended chronologies contain much less memory. Autocorrelations are lower at AC1 and approach zero much quicker, turning negative at AC6 (MXD) and AC7 (TRW) in the Spline detrended data, for example. In the individual detrendings (Hug/NegExp, Spline), the initial autocorrelations, AC1-AC5, are notably larger in TRW ( 0.31 on average) compared to MXD (0.11), revealing increased memory also in these chronology types that are typically used to reconstruct higher frequency climatic changes (Cook and Kairiukstis, 1990).

Comparison of the autocorrelation structure of the RCS and Hug/NegExp chronologies with regional JJA temperatures since 1850 reveals a closer match with MXD (Fig. 3d). AC1-AC10 of the local summer temperatures range from 0.23 to 0.13 , whereas particularly the RCS detrended MXD data contain similar memory, ranging from 0.22 to 0.09 . In contrast, the TRW autocorrelations (0.56-0.22 for RCS and 0.51-0.13 for NegExp) exceed the values of the observations, indicating that reconstructions based on this parameter might overestimate the memory retained in local temperature readings.

The TRW/observational mismatch is particularly striking over the first several lags suggesting potential limitations in retaining high frequency climatic variance and recovery from externally forced extreme deviations in the first $\sim 5$ years. Testing this assertion, however, requires the application of SEA with such extremes. Statistical treatment to remove autocorrelation and pre-whitening the data is not suitable when assessing temperature, as it disables the reconstruction of any lower frequency variance inherent to this climate element (Franke et al., 2013). Modern tree-ring based climate reconstructions thus consider RCS for tree-ring detrending intending to recover the full frequency spectrum of past temperature variability (e.g., Briffa et al., 1992; Büntgen et al., 2011; Cook 
and D’Arrigo, 2000; Cook et al., 2002; D'Arrigo et al., 2006; Esper et al., 2002, 2014; Gennaretti et al., 2014; Luckman and Wilson, 2005; Myglan et al., 2012b; Schneider et al., 2015; Wiles et al., 2014).

\subsection{TRW and MXD signals and memory since $A D 1000$}

The comparison of TRW and MXD variability following 29 major volcanic eruptions of the past millennium reveals substantial differences between the two estimates of response and recovery (Fig. 4a). While MXD shows a significant post-volcanic cooling of $-0.40^{\circ} \mathrm{C}$ in year 1 after the eruptions, the mean TRW deviation at $11 \mathrm{NH}$ sites is less distinct. The TRW based estimates are fairly similar throughout years +1 to +5 , ranging from $-0.13^{\circ} \mathrm{C}$ to $-0.17^{\circ} \mathrm{C}$, and characterized by a larger spread among the differently detrended chronologies (the thin grey curves in Fig. 4a). This somewhat smeared appearance differs from the MXD pattern, which is dominated by a significantly deviating spike in year +1 and reduced but still noticeable cooling in years +2 and +3 . The MXD deviation is quite similar among the different detrendings, and relaxes back to pre-eruption levels in year +4 , though does not exceed $0{ }^{\circ} \mathrm{C}$ before year +7 . The MXD signal also remains distinct in year +1 when dividing the $\mathrm{NH}$ network into high and mid latitude sites, though the amplitude of temperature deviation differs between the subsamples (Fig. 4b and c). For TRW, the signal appears to be limited to the high latitude sites, with the trees from lower latitude, alpine environments showing no significant post-volcanic deviation.

The differing patterns in MXD and TRW likely resulted from changing fractions of climatically explained variance, as well as memory effects arising from varying physiological processes controlling radial increment and cell-wall growth. The overall reduced correlation between the TRW chronologies and local JJA temperatures translates into a reduced post-volcanic deviation in the SEA $\left(-0.17{ }^{\circ} \mathrm{C}\right.$ in year +1 , compared to $-0.40^{\circ} \mathrm{C}$ from the MXD data). This initially reduced deviation then remains at a relatively constant level over the next 4-5 years, perhaps due to carbohydrate storage and remobilization effects controlling TRW (Tranquillini, 1964). The MXD volcanic pattern, on the other hand, is overall more transient and appears to be less affected by physiological and structural influences beyond the immediate impact of air temperature variability. It is further noted, however, that the rather large uncertainties displayed in Fig. 4 not only reflect the noise inherent to the proxy data, but also account for the geographically varying temperature response following large volcanic eruptions (D'Arrigo et al., 2013), as has been demonstrated by Briffa et al. (1998) using a dense network of shorter MXD chronologies from the NH extratropics. These interpretations are further examined in the next section in which the proxy deviations are compared with local temperature data over the shorter post-1850 time interval.

\subsection{Tree-ring and temperature signals since $A D 1850$}

The assessment of recent volcanic eruptions triggering cooling in local temperature data reveals a better fit of MXD compared to TRW (Fig. 5). Both the observational and MXD-based summer temperatures reflect cooling in years 0 to +2 ranging from -0.35 to $-0.61{ }^{\circ} \mathrm{C}$, though maximum deviations are recorded in different years (+2 in MXD, 0 in observations). In contrast, the TRW based estimates do not cohere with the observational data in these years, and do not deviate substantially from climatology $(-0.21$ to $-0.31{ }^{\circ} \mathrm{C}$ in years 0 and +1 ), indicating the limited skill of this tree-ring parameter to reflect distinct inter-annual temperature variations. For MXD, it appears somewhat surprising how well the estimates compare with the instrumental cooling magnitude, as the volcanic events aligned in the SEA are limited to yearly anomalies that are colder than $-0.5^{\circ} \mathrm{C}$ in the local observational data
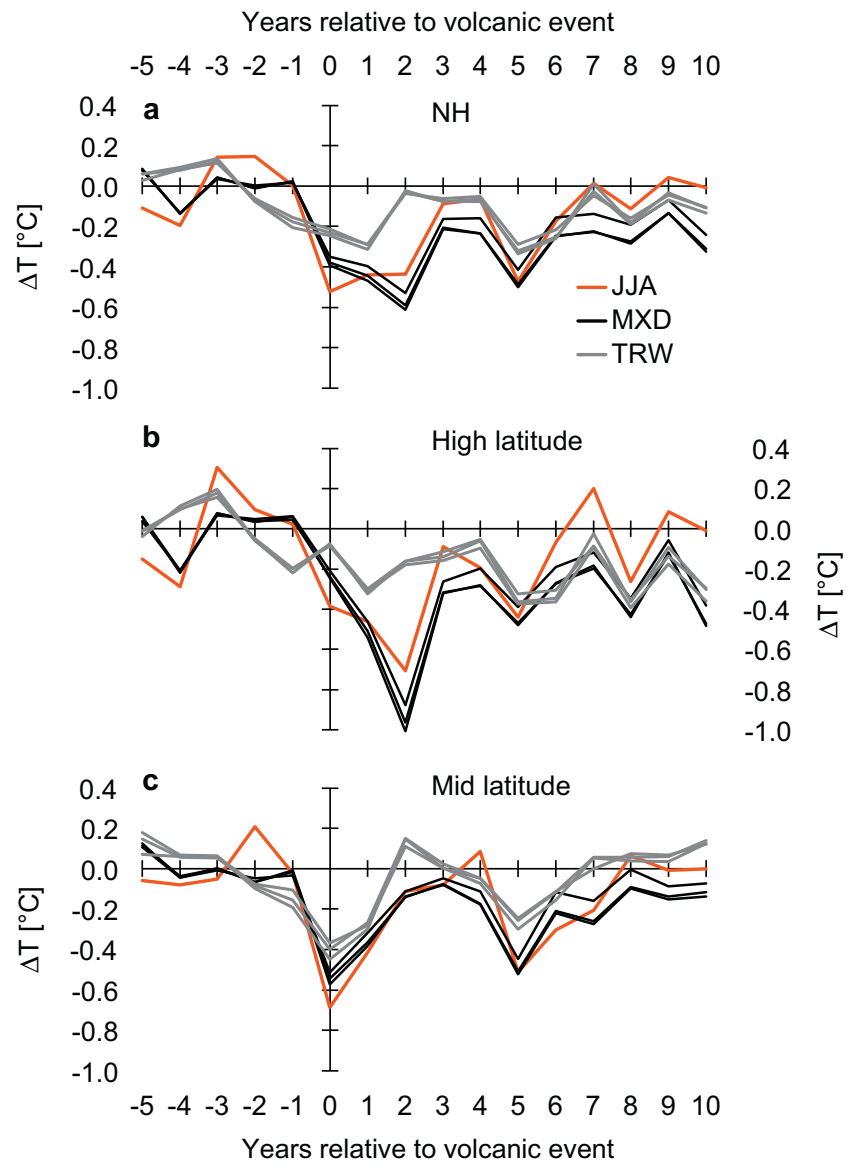

Fig. 5. Post-volcanic cooling in proxy and observational data. (a) SEA of the mean MXD (black), TRW (grey), and JJA temperature data (red) from $11 \mathrm{NH}$ sites aligned by 13 volcanic eruptions since 1850 . At each site, the events triggering $>-0.5^{\circ} \mathrm{C}$ cooling in years $0,+1$, or +2 in the observational data were considered. From a total of 136 potential cases in all $11 \mathrm{NH}$ tree sites, only $85(63 \%)$ reached this criterion, i.e. 51 cases did not exceed $-0.5^{\circ} \mathrm{C}$ at a particular grid point. Single black and grey curves represent different detrendings (Hug/NegExp, Spline, RCS). (b) As in (a), but for the sites located north of $63^{\circ} \mathrm{N}$. (c), As in (a), but for the sites locate south of $53^{\circ} \mathrm{N}$.

(Methods). This selection procedure involved a reduction of the SEA aligned volcanic events by $37 \%$ unrelated to local cooling in the gridded temperature data.

The differing responses in years 0 and +2 in the proxy and instrumental data is further explored by dividing the network into sites north of $63^{\circ} \mathrm{N}$ and south of $53^{\circ} \mathrm{N}$ (Fig. $5 \mathrm{~b}$ and c). When applying this separation an instantaneous response (year 0) to volcanic activity is recorded at the mid latitude sites, and a delayed response $($ year +2$)$ at the high latitude sites. While the mid latitude observational temperature response is closely reflected in both the regional TRW and MXD data, the high latitude cooling is only retained in the MXD data. The high latitude TRW chronologies do not indicate any post-volcanic variance differing from other, un-forced years, underscoring the limited skill of this parameter to reconstruct externally forced extremes in boreal environments. This conclusion is, however, constrained by the limited number of volcanic events leaving a cooling signature in the local instrumental data since 1850 . Further explaining the spatially differing post-volcanic patterns in the observational and MXD data requires a spatially resolved analysis of NH temperature fields (Schneider et al., 2015), which is beyond the scope of this current analysis focusing on parameter-specific memory effects.

We finally show the SEA results, based on aligning the tree-ring data by the locally coldest and warmest summers since 1850 , to reinforce the $(i)$ reduced temperature amplitude retained in the 
Years relative to minimum temperature
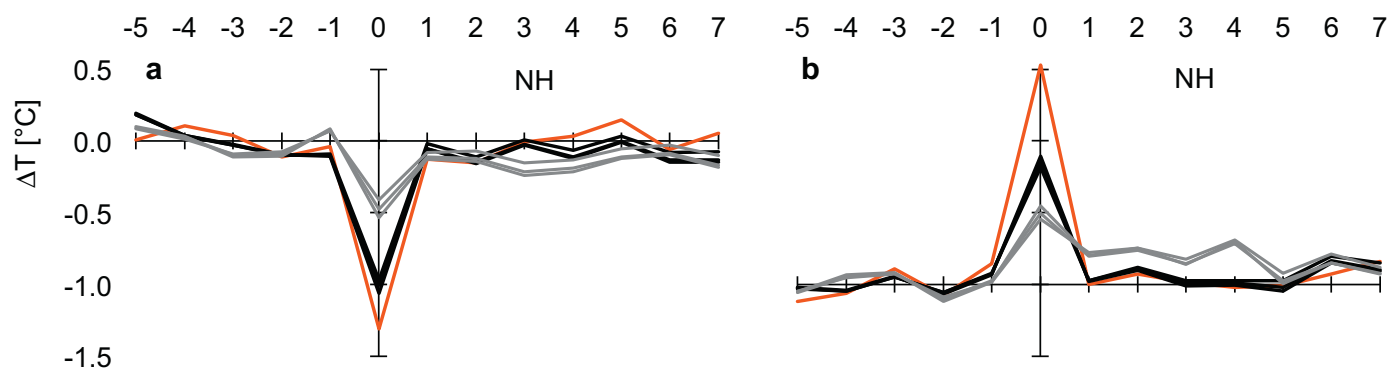

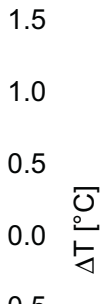
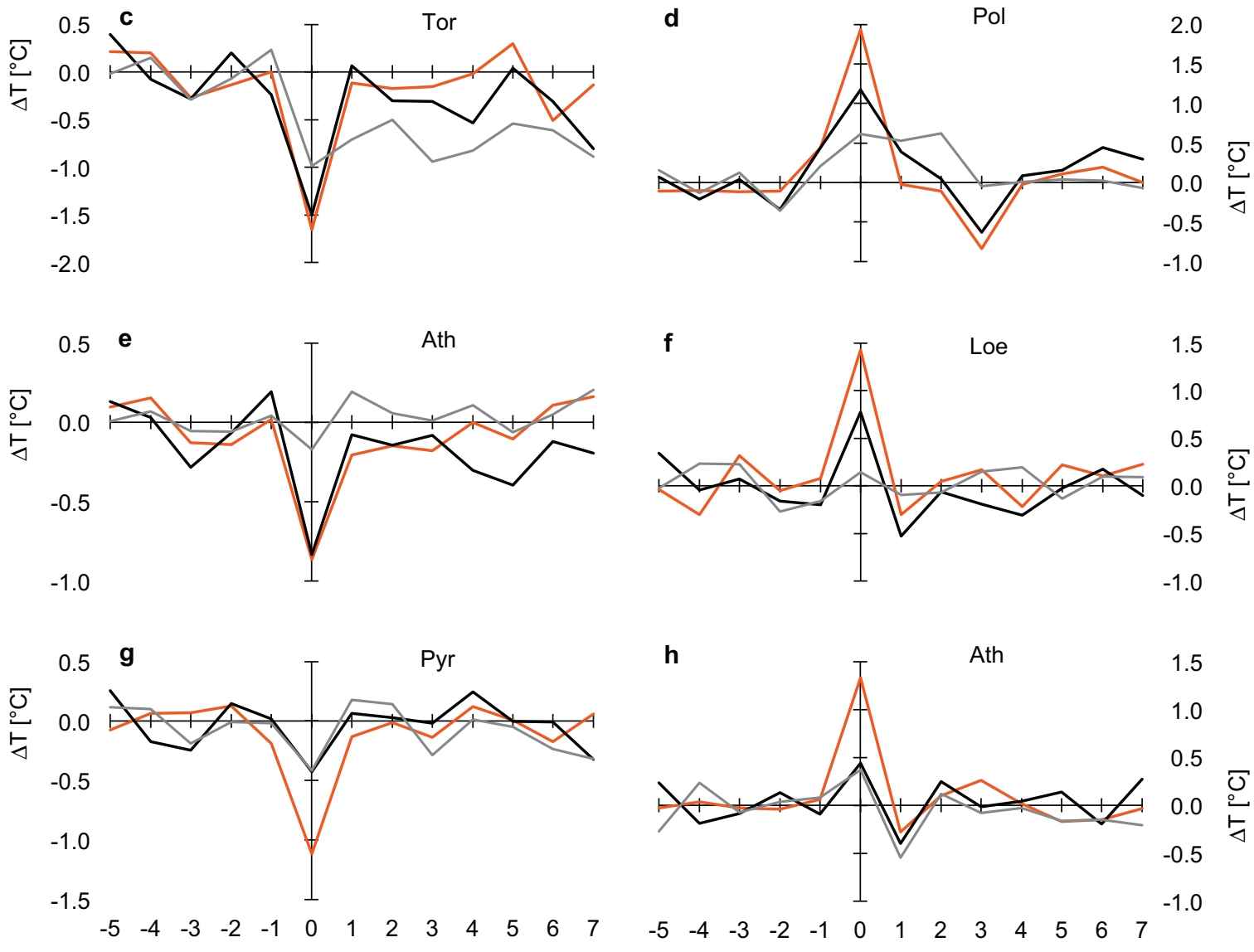

Years relative to minimum temperature

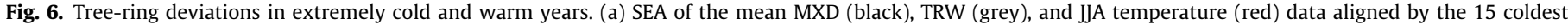
summers at the local grid points since 1850. (b) Same as in (a), but for the 15 warmest summers in each region. (c-h) MXD and TRW deviations in selected NH sites.

TRW network, and (ii) large variability of TRW and MXD patterns among $\mathrm{NH}$ sites (Fig. 6). While the reduced climatically explained variance in the TRW chronologies $\left(r-^{2}=0.11\right.$ with JJA temperatures) easily explains the severe underestimation of extreme JJA temperature deviations $\left(\Delta \mathrm{T}=0.84^{\circ} \mathrm{C}\right.$ in cold and $1.03^{\circ} \mathrm{C}$ warm years; Fig. $6 a$ and $b$ ), the spatially variable response patterns cannot be related to a single controlling factor, such as species composition or site location. If anything, site variability remains as an unexplained characteristic of the proxy network: Tor (Sweden, pine) and Pol (Russia, larch) show good coherence in MXD, but memory effects in TRW (Fig. 6c and d); Ath (Canada, spruce) and Loe (Switzerland, larch) show good coherence in MXD, but no signal in TRW (Fig. 6e and f); and Pyr (Spain, pine) and Ath (Canada, spruce) show weak signals in both MXD and TRW (Fig. $6 g$ and $h$ ). It is important to keep these differences in mind when aggregating larger proxy networks and interpreting their common response (Esper et al., 2012a).

\section{Conclusion}

Comparison of long MXD and TRW chronologies from 11 sites in the NH give insight into parameter-specific responses and memory effects. We found a temporally extended response (up to 6 years) in TRW subsequent to 29 volcanic eruptions of the past millennium. In contrast, the MXD response is strongest in the first post-volcanic year $\left(-0.40^{\circ} \mathrm{C}\right.$ on average $)$ and does not substantially extend beyond the third post-volcanic year. Carbohydrate storage and remobilization likely control the parameter-specific memory effects, increasing the autocorrelation in TRW chronologies beyond the memory inherent to target summer temperature data. While 
the autocorrelation structure of tree-ring chronologies is highly dependent on the detrending method, memory in TRW is generally larger than in MXD over the first 10 to 20 lags.

Besides the memory effects, the TRW extremes also appear to be reduced in comparison to the MXD deviations over the past 1000 years. TRW-based cooling estimates only reach $-0.17^{\circ} \mathrm{C}$ in the first post-volcanic year, compared to $-0.40^{\circ} \mathrm{C}$ using MXD. Comparisons with instrumental summer temperature data over the post-1850 period support this conclusion, with the MXD estimates being in line with the observations, and the TRW estimates indicating smaller cooling effects. There is no sign that MXD systematically over or underestimates the cooling response to volcanic eruptions (Tingley et al., 2014). The assessments over this much shorter time interval also indicate a better correlation between TRW and observational data in mid latitude locations south of $53^{\circ} \mathrm{N}$, but a diminished signal in high latitude locations north of $63^{\circ} \mathrm{N}$. This conclusion, however, rests on fewer data points including only 13 volcanic events since 1850 , and is not supported by the findings based on data over the past millennium. The latter indicates the high (not mid) latitude TRW data contain a stronger post-volcanic signal, though contaminated by memory effects in subsequent years.

Both characteristics of TRW - the increased memory ( $\sim 6$ years) and reduced variability ( $\sim$ half of the MXD variance) - likely bias post-volcanic cooling estimates, and perhaps other disturbance signals (Esper et al., 2007a). While our study also indicates a large variability among tree sites, it demonstrates the strength of MXD data for assessing pulse-like disturbance events beyond the period covered by observational data. The application of individual detrending methods that emphasize higher frequency variance in resulting chronologies probably does not resolve the limitation of TRW to retain unbiased estimates of extreme events.

\section{Acknowledgements}

Most of the MXD data was measured at WSL in Birmensdorf, Switzerland. We thank all colleagues for developing millennial-length chronologies and making data available. Lamont contribution \#7918. Supported by the JGU Mainz "Inneruniversitäre Forschungsförderung".

\section{References}

Anchukaitis, K., et al., 2012. Tree rings and volcanic cooling. Nat. Geosci. 5, 836-837. Briffa, K.R., Jones, P.D., Bartholin, T.S., Eckstein, D., Schweingruber, F.H., Karlén, W. Zetterberg, P., Eronen, M., 1992. Fennoscandian summers from AD 500: temperature changes on short and long timescales. Clim. Dyn. 7, 111-119.

Briffa, K.R., Jones, P.D., Schweingruber, F.H., Shiyatov, S.G., Cook, E.R., 1995. Unusual 20th- Century Summer Warmth in a 1000-Year Temperature Record from Siberia. Nature 376, 156-159.

Briffa, K.R., Jones, P.D., Schweingruber, F.H., Osborn, T.J., 1998. Influence of volcanic eruptions on Northern Hemisphere summer temperature over the past 600 years. Nature 393, 450-455.

Büntgen, U., Frank, D.C., Nievergelt, D., Esper, J., 2006. Summer temperature variations in the European Alps. J. Clim. 19, 5606-5623, AD 755-2004.

Büntgen, U., Frank, D., Grudd, H., Esper, J., 2008. Long-term summer temperature variations in the Pyrenees. Clim. Dyn. 31, 615-631.

Büntgen, U., et al., 2011. European climate variability and human susceptibility over the past 2500 years. Science $331,578-582$

Bunde, A., Büntgen, U., Ludescher, J., Luterbacher, J., von Storch, H., 2013. Is there memory in precipitation? Nature Clim. Change 3, 174-175.

Cole-Dai, J., 2010. Volcanoes and climate. WIREs Clim. Change 1, 824-839.

Cook, E.R., 1985. A time series analysis approach to tree-ring standardization. In: Ph.D. Dissertation. Tucson, University of Arizona, pp. 171

Cook, E.R., Peters, K., 1981. The smoothing spline: a new approach to standardizing forest interior tree-ring width series for dendroclimatic studies. Tree-Ring Bull. 41, 45-53.

Cook, E.R., Kairiukstis, L.A. (Eds.), 1990. Kluwer Academic Publishers, Dordrecht, p. 394

Cook, E.R., Peters, K., 1997. Calculating unbiased tree-ring indices for the study of climatic and environmental change. Holocene 7, 361-370.

Cook, E.R., Buckley, B.M., D’Arrigo, R.D., Peterson, M.J., 2000. Warm-season temperatures since $1600 \mathrm{BC}$ reconstructed from Tasmanian tree rings and their relationship to large-scale sea surface temperature anomalies. Clim. Dyn. 16, 79-91.

Cook, E.R., Palmer, J.G., D’Arrigo, R.D., 2002. Evidence for a 'Medieval Warm Period' in a 1100 year tree-ring reconstruction of past austral summer temperatures in New Zealand. Geophys. Res. Lett. 29, http://dx.doi.org/10.1029/2001GL014580

D’Arrigo, R., Wilson, R., Jacoby, G., 2006. On the long-term context for late twentieth century warming. J. Geophys. Res. 111, http://dx.doi.org/10.1029/ 2005JD006352

D’Arrigo, R., Wilson, R., Tudhope, A., 2009. Impact of volcanic forcing on tropical temperatures during the last four centuries. Nature GeoSci. 2, 51-56.

D’Arrigo, R., Wilson, R., Anchukaitis, K.J., 2013. Volcanic cooling signal in tree ring temperature records for the past millennium. J. Geophys. Res. 118, http://dx. doi.org/10.1002/jgrd.50692

Esper J., 2014. Memory effects in tree-ring width and maximum latewood density in response to volcanic eruptions: evidence from Northern Fennoscandia. In: Wilson, R.J.S., et al. (Eds.), Tree rings in archaeology, climatology and ecology. TRACE, vol. 13, in press.

Esper, J., Cook, E.R., Schweingruber, F.H., 2002. Low-frequency signals in long tree-ring chronologies and the reconstruction of past temperature variability. Science 295, 2250-2253.

Esper, J., Cook, E.R., Krusic, P.J., Peters, K., Schweingruber, F.H., 2003. Tests of the RCS method for preserving low-frequency variability in long tree-ring chronologies. Tree-Ring Res. 59, 81-98.

Esper, J., Frank, D.C., Wilson, R.J.S., Briffa, K.R., 2005. Effect of scaling and regression on reconstructed temperature amplitude for the past millennium. Geophys. Res. Lett. 32, http://dx.doi.org/10.1029/2004GL021236

Esper, J., Büntgen, U., Frank, D.C., Nievergelt, D., Liebhold, A., 2007a. 1200 years of regular outbreaks in alpine insects. Proc. R. Society B 274, 671-679.

Esper, J., Büntgen, U., Frank, D., Pichler, T., Nicolussi, K., et al., 2007b. Updating the tyrol tree- ring dataset. In: Haneca, K. (Ed.), Tree rings in archaeology, climatology and ecology, vol. 5. TRACE, pp. 80-85.

Esper, J., Frank, D.C., Büntgen, U., Verstege, A., Hantemirov, R.M., Kirdyanov, A.V., 2010. Trends and uncertainties in Siberian indicators of 20th century warming. Global Change Biol. 16, 386-398.

Esper, J., Büntgen, U., Timonen, M., Frank, D.C., 2012a. Variability and extremes of Northern Scandinavian summer temperatures over the past millennia. Global Planet. Change 88-89, 1-9.

Esper, J., et al., 2012b. Orbital forcing of tree-ring data. Nature Clim. Change 2, $862-866$.

Esper, J., Büntgen, U., Luterbacher, J., Krusic, P., 2013a. Testing the hypothesis of post-volcanic missing rings in temperature sensitive dendrochronological data. Dendrochronologia 13, 216-222.

Esper, J., Schneider, L., Krusic, P.J., Luterbacher, J., Büntgen, U., Timonen, M., Sirocko, F., E, Zorita 2013, 2013b. European summer temperature response to annually dated volcanic eruptions over the past nine centuries. Bull. Volcanol. 75, 736, http://dx.doi.org/10.1007/s00445-013-0736-z

Esper, J., Düthorn, E., Krusic, P., Timonen, M., Büntgen, U., 2014. Northern European summer temperature variations over the Common Era from integrated tree-ring density records. J. Quat. Sci. 29, 487-494.

Fischer, E.M., Luterbacher, J., Zorita, E., Tett, F.B., Casty, C., Wanner, H., 2007. European climate response to tropical volcanic eruptions over the last half millennium. Geophysic. Res. Lett. 34, http://dx.doi.org/10.1029/ 2006GL027992, L05707.

Frank, D., Esper, J., 2005. Characterization and climate response patterns of a high-elevation, multi-species tree-ring Network in the European Alps. Dendrochronologia 22, 107-121.

Frank, D., Büntgen, U., Böhm, R., Maugeri, M., Esper, J., 2007a. Warmer early instrumental measurements versus colder reconstructed temperatures: shooting at a moving target. Quat. Sci. Rev. 26, 3298-3310.

Frank, D., Esper, J., Cook, E.R., 2007b. Adjustment for proxy number and coherence in a large-scale temperature reconstruction. Geophys. Res. Lett. 34, http://dx. doi.org/10.1029/2007GL030571

Franke, J., Frank, D., Raible, C.C., Esper, J., Bronnimann, S., 2013. Spectral biases in tree-ring climate proxies. Nature Clim. Change 3, 360-364.

Fritts, H.C., 1976. Tree Rings and Climate. Academic Press, London, pp. 567.

Gao, C., Robock, A., Ammann, C., 2008. Volcanic forcing of climate over the past 1500 years: an improved ice core-based index for climate models. J. Geophys. Res. 113, http://dx.doi.org/10.1029/2008JD010239, D23111.

Gennaretti, F., Arseneault, D., Nicault, A., Perreault, L., Beígin, Y., 2014. Volcano-induced regime shifts in millennial tree-ring chronologies from northeastern North America. PNAS 111, 10077-10082.

Hammer, C.U., Clausen, H.B., Dansgaard, W., 1980. Greenland ice sheet evidence of post-glacial volcanism and its climatic impact. Nature 288, 230-235.

LaMarche, V.C., Hirschboeck, K.K., 1984. Frost rings in trees as records of major volcanic eruptions. Nature 307, 121-126.

Lavigne, F., Source of the great, A.D., et al., 2013. 1257 mystery eruption unveiled Samalas volcano, Rinjani Volcanic Complex, Indonesia. PNAS 110, 16742-16747.

Lee, T.C., Zwiers, F.W., Tsao, M., 2008. Evaluation of proxy-based millennial reconstruction methods. Clim. Dyn. 31, 263-281

Luckman, B.H., Wilson, R.J.S., 2005. Summer temperatures in the Canadian Rockies during the last millennium: a revised record. Clim. Dyn. 24, 131-144.

Matalas, N.C., 1962. Statistical properties of tree ring data. Hydrol. Sci. J. 7, 39-47.

Melvin, T.M., Grudd, H., Briffa, K.R., 2013. Potential bias in updating tree-ring chronologies using regional curve standardisation: re-processing 1500 years of Torneträsk density and ring-width data. Holocene 23, 364-373. 
Meko, D.M., 2015. Applications of Box-Jenkins methods of time series analysis to the reconstruction of drought from tree rings. In: Ph.D. Dissertation. Tucson, University of Arizona, pp. 149.

Meko, D.M., et al., 2007. Medieval drought in the upper Colorado River basin. Geophys. Res. Lett. 34, http://dx.doi.org/10.1029/2007GL029988

Myglan, V.S., Oidupaa, O.C., Vaganov, E.A., 2012a. A 2367-year tree-ring chronology for the Altai-Sayan region (Mongun-Taiga Mountain Massif). Archaeology. Ethnology Anthropol. Eurasia. 40, 76-83.

Myglan, V.S., Zharnikova, O.A., Malysheva, N.V., Gerasimova, O.V., Vaganov, E.A., Sidorov, O.V., 2012b. Constructing the Tree-Ring Chronology and Reconstructing Summertime Air Temperatures in Southern Altai for the Last 1500 Years. Geogr. Natural Res. 33, 22-30.

Newhall, C.G., Self, S., 1982. The volcanic explosivity index (VEI): an estimate of explosive magnitude for historical volcanism. J. Geophys. Res. 87, 1231-1238.

Oppenheimer, C., 2011. Eruptions that Shook the World. Cambridge, Cambridge University Press, pp. 408.

Pallardy, S.G., 2015. Physiology of Woody Plants. San Diego, Academic Press, pp. 464.

Panofsky, H.A., Brier, G.W., 1958. Some applications of statistics to meteorology. University Park, Pennsylvania, pp. 224

Robock, A., 2000. Volcanic eruptions and climate. Rev. Geophys. 38, 191-219.

Salzer, M.W., Hughes, M.K., 2007. Bristlecone pine tree rings and volcanic eruptions over the last 5000 yr. Quat. Res. 67, 57-68.

Schneider, L., Smerdon, J.E., Büntgen, U., Wilson, R.J.S., Myglan, V.S., Kirdyanov, A.V., Esper, J., 2015. Revising northern hemispheric temperature history back to AD 600. Geophys. Res. Lett. 42, http://dx.doi.org/10.1002/2015GL063956

Schweingruber, F.H., Fritts, H.C., Bräker, O.U., Drew, L.G., Schaer, E., 1978. The X-ray technique as applied to dendroclimatology. Tree-Ring Bull. 38, 61-91.

Schweingruber, F.H., Bartholin, T., Schär, E., Briffa, K.R., 1988.

Radiodensitometric-dendroclimatological conifer chronologies from Lapland (Scandinavia) and the Alps (Switzerland). Boreas 17, 559-566.
Schulman, E., 1956. Dendroclimatic Changes in Semiarid America. Tucson, University of Arizona Press, pp. 142.

Sear, C.B., Kelly, P.M., Jones, P.D., Goodess, C.M., 1987. Global surface temperatures responses to major volcanic eruptions. Nature 330, 365-367.

Self, S., Rampino, M.R., Barbera, J.J., 1981. The possible effects of large 19th and 20th century volcanic eruptions on zonal and hemispheric surface temperatures. J. Volcanol. Geotherm. Res. 11, 41-60.

Siebert, L., Simkin, T., Kimberly, P., 2011. Volcanoes of the world. University of California Press, London, pp. 551.

Smerdon, J.E., Coats, S., Ault, T.R., 2015. Model-dependent spatial skill in pseudoproxy experiments testing climate field reconstruction methods for the Common Era. Clim. Dyn., in press.

Timmreck, C., 2012. Modeling the climatic effects of large explosive volcanic eruptions. WIREs Clim. Change 3, 545-564.

Tingley, M.P., Stine, A.R., Huybers, P., 2014. Temperature reconstructions from tree-ring densities overestimate volcanic cooling. Geophys. Res. Lett. 41, $7838-7845$.

Tranquillini, W., 1964. The physiology of plants at high altitudes. Annual Rev. Plant Phys. 15, 345-362.

Vaganov, E.A., Hughes, M.K., Shashkin, A.V., 2006. Growth Dynamics of Conifer Tree Rings: Images of Past and Future Environments. Springer, Berlin, pp. 358.

Von Storch, H., Zorita, E., Jones, J.M., Dimitriev, Y., González-Rouco, F., Tett, S.F., 2004. Reconstructing past climate from noisy data. Science 306, 679-682.

Wegmann, M., Brönnimann, S., Bhend, J., Franke, J., Folini, D., Wild, M., Luterbacher J., 2014. Volcanic influence on European summer precipitation through monsoons: possible cause for years without summer. J. Clim. 27, 3683-3691.

Wiles, G.C., D’Arrigo, R.D., Barclay, D., Wilson, R.S., Jarvis, S.K., Vargo, L., Frank, D., 2014. Surface air temperature variability reconstructed with tree rings for the Gulf of Alaska over the past 1200 years. The Holocene 24, 198-208. 